American Journal of

Supply Chain Management

(AJSCM)

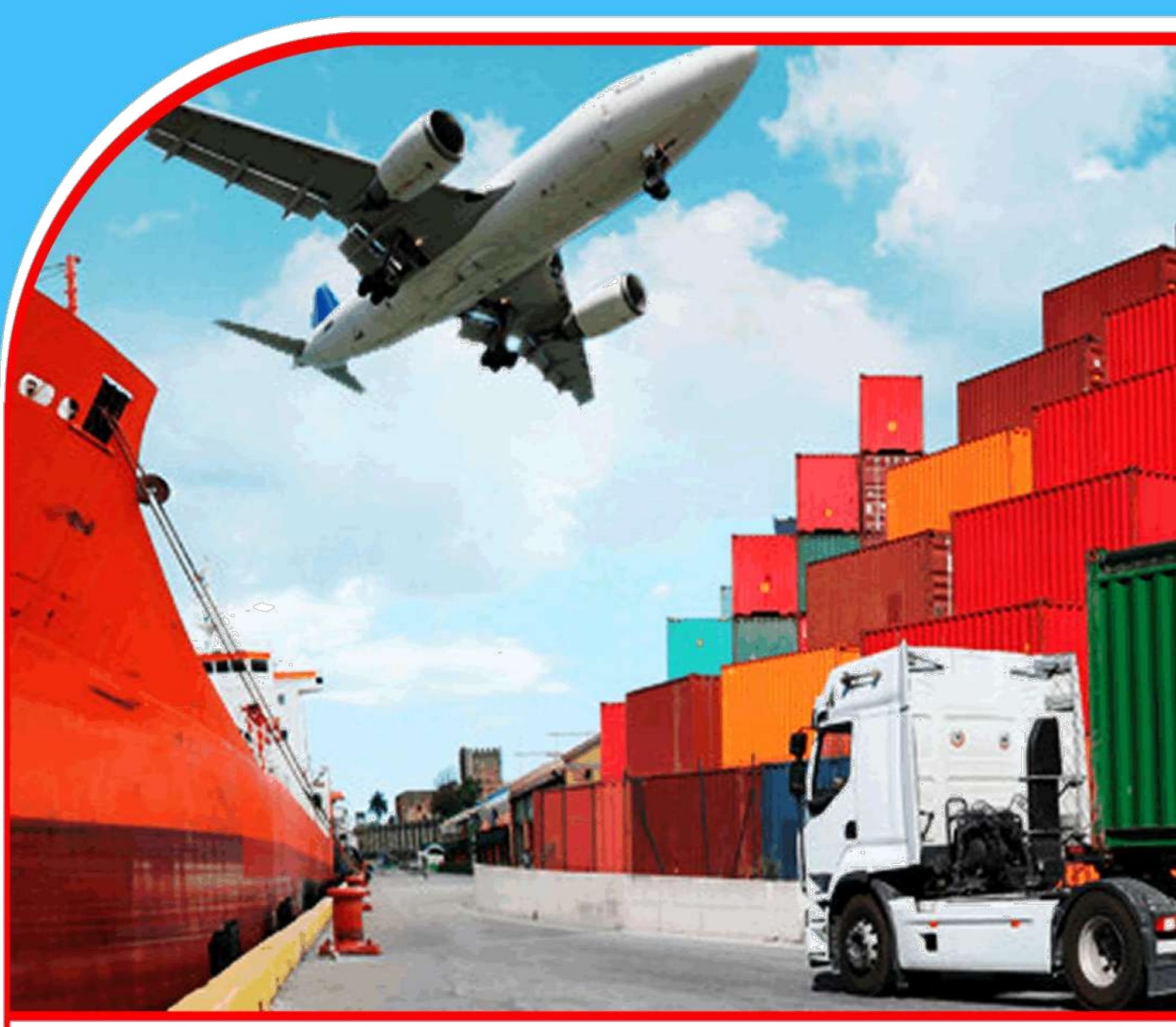

The implications of covid-19 on the shipping/oil tanker market.

Paul Ogoun (PhD)

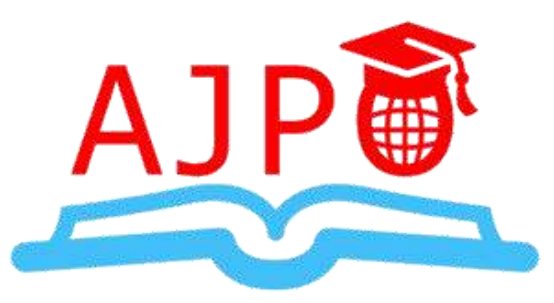




\title{
The implications of covid-19 on the shipping/oil tanker market.
}

\author{
Paul Ogoun (PhD)
}

\author{
Author's Email: paulmandelaogoun@gmail.com
}

\begin{abstract}
Purpose: This aims at analyzing the implications of covid-19 on the shipping/oil tanker market.

Methodology: In order to attain the aim of this study, findings and data are curated from existing literatures, documents, policies, etc. This implies that desk review is the methodology applied in this study where the researcher made use of secondary sources of data as against primary source of data.
\end{abstract}

Findings: In the study, it was found that covid-19 brought about a shortage in the rate of demands for good thereby causing an unbalance in the rate of supply over demand at a time which directly brought about a huge decline in shipping/oil tanker transportation. The study also found that irrespective of the huge decline in the rate of shipping/oil tanker transportation brought about by low demand in comparison with supply; shipping/oil tanker was patronized by dealers for the purpose of storage of products. Also, the study found that seaborne trade fell downward from above $3 \%$ to below a negative $8 \%$ and at a bdp rate of $100 \mathrm{~m}$, the demand was $3 \%$ higher than the global supply which in 2019 was at about $97 \%$. However, in the second quarter of 2020 the supply leads demand at over 28M bdp and a 13\% increase in the demand year-on-year when compared to a fall of $3.9 \%$ in the supply year-on-year.

Recommendation: The study recommends that appropriate forecasting methods and proper liaison with global health will aid in averting or ameliorating the risks and negative impacts brought on shipping/oil tanker market by covid-19.

Keywords: Covid-19, Shipping, Oil tanker, Implications, Market 


\section{Introduction}

At the inception of covid-19, in some quarters it was not considered the status and severity it gathered after specific period of its existence. The advent of covid-19 has been a great shock to various countries whether with a robust health system or with a dilapidated one, it has been a global adversary since it first broke out in Wuhan, China in December, 2019. Even as a global health crisis, no country is relenting in its effort to safeguard its territory and people therein from the horrible effects of the disease. The goal has been to combat the pandemic and get rid of it, if possible ${ }^{1}$.

Covid-19, which is the short form of Coronavirus disease 2019, is a disease with high transmission rate and also viral infection that is pathogenic in nature. The cause of Covid-19 has been related severe acute respiratory syndrome coronavirus 2 (SARS-CoV-2), which was first identified in Wuhan, China in December, 2019 and currently, it is domed as a global health crisis, as it has spread around the universe. Based on genomic analysis and findings, "SARS$\mathrm{CoV}-2$ is phylogenetically related to severe acute respiratory syndrome like bat viruses, therefore bats could be the possible primary reservoir"2.

In the same manner like most other global health crisis in the past, Covid-19 makes its entrant without any previous warnings. It is on such ground that it was not out of place to find that most countries across the globe were not having any preparation on how to contain it or eradicate its spread and transmission in good speed. Global health crisis is a form of disease outbreak that affects all parts of the world over a given period of time ${ }^{3}$. In most cases, in bid to contain them, they affect socio-economic, socio-political, socio-psychological structure and well-being of any given society and its people. Obviously, covid-19 comes in the same dimension, character and implications.

It is on the basis of the foregoing that this study sets out to make an analysis of the implications of covid-19 on the shipping/oil tanker market. The study made emphasis to global market while taking direct examples from the USA, China, Europe, etc.

\section{Overview of Shipping/Oil Tanker Market and the Implications of Covid-19}

Maritime transport underpins global supply chain linkages and economic interdependency with shipping and ports estimated to handle over 80 per cent of global merchandise trade by volume

\footnotetext{
${ }^{1}$ World Health Organization, Laboratory testing for coronavirus disease 2019 (COVID-19) in suspected human cases: interim guidance, (2020)

${ }^{2}$ Adnan, M. \& Siddiquea S.R; COVID-19 infection: Origin, transmission, and characteristics; Journal of Advanced Research, 24 (2), 91-98, (2020) doi.org/10.1016/j.jare.2020.03.005
}

\footnotetext{
${ }^{3}$ Dzau, V, Fuster, V, \& Frazer, J., Investing in global health for our future. N Engl J Med Overseas Ed; 377:1292-
} 6. (2017); doi:10.1056/NEJMsr1707974 
and more than 70 per cent by value. As a result, when disruptive factors such as pandemics occur, the sector works as a transmission channel that sends shockwaves across supply chains and regions. Disrupted transport networks and supply chains can significantly undermine world trade and economic activity ${ }^{4}$.

At the heat of the rapid spread and transmission of covid-19, the pandemic has had a huge impact on the shipping market and oil tankers with a fall in the demand for goods. As at the inception of covid-19; it was thought that the impacts were limited to China but with time the impacts escalated across populations and territories. Across the maritime segments, there was a cut in the supply of labour which eventually affected the trade rates. Data from market intelligence showed that service vessels value revealed a drastic drop in the rate of demand for the crude tankers 5 .

\section{Chinese Crude Tanker Demand}

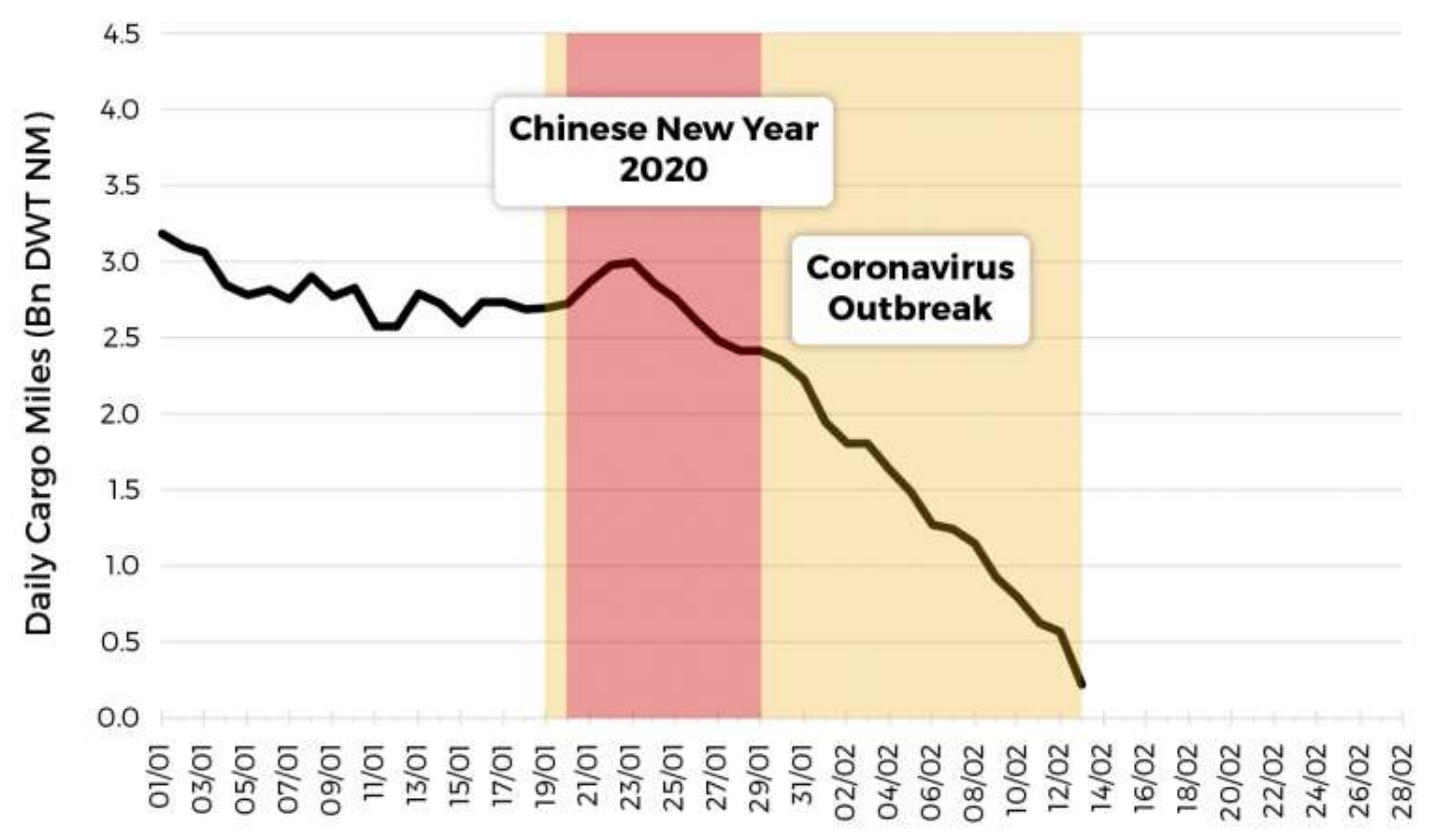

-Middle East to China Route for VLCC, Suezmax and Aframax Tankers

Source: VesselsValue February 2020

Q VesselsValue

\section{Fig.1 2020 Chinese Crude Tanker Demand}

Source: Vessels Value ${ }^{6}$

\footnotetext{
${ }^{4}$ British Ports Association, UK Ports: Coronavirus Economic Recovery Plan 2020 and Beyond. London; 2020

${ }^{5}$ Coutroubis, A. D. Menelaou, A. A. and Adami, E. 'Impact of coronavirus disease (covid-19) on seafarers' life and well-being', International Journal of TROPICAL DISEASE \& Health 41(21): 16-27, 2020;

${ }^{6}$ Vessels Value, 'Coronavirus causes China crude tanker demand to plummet', 2020; Available on https://www.oilandgasmiddleeast.com/products-services/36282-coronavirus-causes-china-crude-tankerdemand-to-plummet-vesselsvalue
} 
For example, the Chinese crude tankers dropped from an over 3 billion tonne miles per day a year before covid-19 to almost nothing few months after the index case of the pandemic. And within a space of 12 months, the cost of hiring a crude carrier (VLCC) per day increased by more than $20 \%$ whereas there was about $70 \%$ decrease in the amount of spot earnings. It is suggested that the impacts on shipping and oil tanker is owed to rapid falls in the demand for goods, oil, production and exports, etc. ${ }^{7}$

Total fleet demolition activity

Million DWT, past 24 months

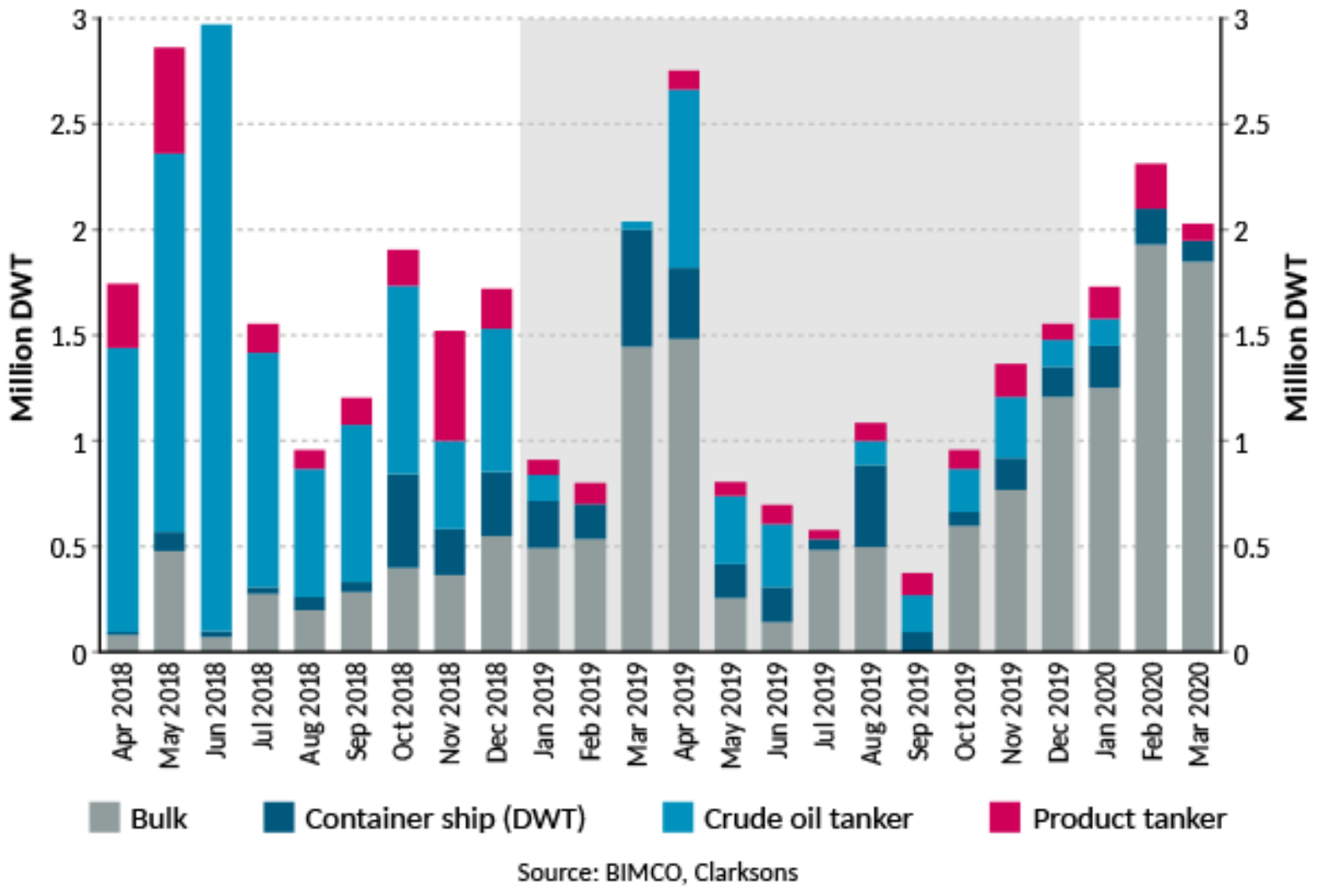

Fig.2 Demolition of Fleets

Source: Bimco $^{8}$

\footnotetext{
${ }^{7}$ Jallal, C. 'Quantifying the impact of covid-19 on tanker trades'; Riviera, 2020; Adele, B. 'The Impact of covid19 on global shipping: Part 1, system shock'; Ship Technology; 2020
${ }^{8}$ BIMCO, 'Coronavirus is disrupting the supply of ships as well as demand'; 2020; Available on https://www.bimco.org/news/market analysis/2020/20200403 coronavirus is disrupting the supply of shi ps as well as demand




\section{Total fleet contracting activity}

Million DWT, past 24 months

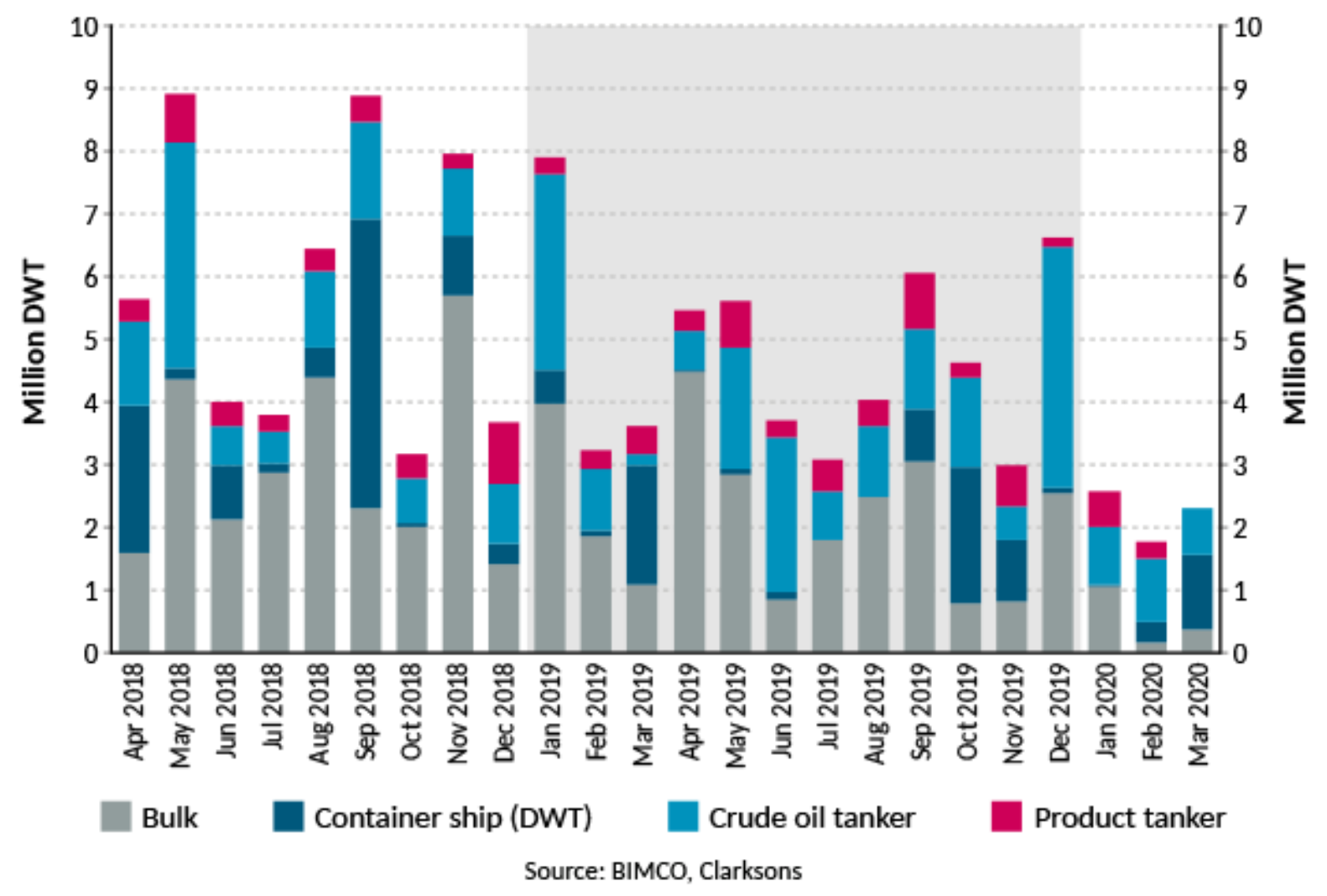

Fig.3 Fleet Contracting Activities

\section{Source: $\mathrm{BIMCO}^{9}$}

It is found that the overall rates for tanker freight were pushed further downward in 2020 when compared to the rates a year earlier. BIMCO noted that earnings made from the Perisian Gulf drastically dropped by more than $80 \%$. Generally, seaborne trade fell downward from above $3 \%$ to below a negative $8 \%$. As of 2019 , the balance in crude oil was favourable when demand and supply are weighed accordingly. At a bdp rate of $100 \mathrm{~m}$, the demand was 3\% higher than the global supply which in 2019 was at about $97 \%$. However, the shocking event occurred in the second quarter of 2020 when the supply leads demand at over $28 \mathrm{M}$ bdp and a $13 \%$ increase in the demand year-on-year when compared to a fall of $3.9 \%$ in the supply year-on-year ${ }^{10}$.

Since there is an excessive supply when compared to demand for crude oil to the extent that traders are pushed on to store the cheap crude oil. In comparison with the VLCC 's earnings in 2019 which was at below $\$ 45,000$ per day; the earnings for Crude carriers (VLCC) spiked on an average above $\$ 150,000$ and $\$ 170,000$ per day for the months of March and April 2020 respectively. It follows that the demand for tankers were as well drastically affected

\footnotetext{
${ }^{9}$ BIMCO, 2020

${ }^{10}$ Jallal, C. 'Quantifying the impact of covid-19 on tanker trades'; Riviera, 2020; Philip, D. and Simon, H. Covid-
} 
as the average speed of crude tanker measuring between $0.5 \%$ and $0.9 \%$ between 2019 and 2020 falls back to 11.7 knots measuring $0.1 \%$ average speed ${ }^{11}$. Countries having relatively higher shares of backward value chain participation are likely to be the most vulnerable. Meanwhile any disproportionately negative impact on vulnerable economies such as SIDS and landlocked developing countries (LLDCs) and the least developed countries (LDCs) where logistical and developmental challenges are already significant, can be detrimental for their sustainable development aspirations ${ }^{12}$.

The Coronavirus disease (COVID-19) triggered a global health and economic crisis with wideranging implications for maritime transport and trade. Restrictions introduced in response to the pandemic have caused disruptions affecting ports, shipping and supply chains. Various industries faced challenges along their supply chain such as raw material shortages, lead time issues, ocean blank sailings, port closures, reduced working hours at ports, equipment and labor shortages, as well as truck/transport capacity constraints. These obstacles undermine the smooth movement of trade flows and supply chain operations and can significantly erode the transport services trade liberalization and trade facilitation gains achieved over the years ${ }^{13}$.

At the inception of covid-19; some traders resorted to storage of crude oil and products at sea as a means to maximise income and avert risks. This implies that every available tanker was seen as a means of storage to the extent that MR product tankers were employed for the purpose of being used for floating storage. By the second quarter of 2020, over $10 \%$ of the tanker fleet were used for storage purposes - thus, they are deemed as laden vessels since they had been stationary for 14 days or more ${ }^{14}$.

As at the 2020 during the fresh blows of covid-19, the prices for crude oil were in the negative whereby the benchmark for international crude oil trading in the New York suddenly became negative at $-\$ 37$ for the first time since recorded history began. Generally, a negative price signifies that there are abnormal circumstances which bend the crude oil sellers into being interested to pay hugely to revert the condition. By the fact that covid-19 slowed down crude consumptions, the storage capacity of crude oil got to its limitations

${ }^{11}$ Adele, B. 'The Impact of covid-19 on global shipping: Part 1, system shock'; Ship Technology; 2020

12 Philip, D. and Simon, H. Covid-19 container shipping market and operational issues update. Drewry Special Webinar. 14 May, 2020

${ }^{13}$ Adnan, M. \& Siddiquea S. R. (2020) COVID-19 infection: Origin, transmission, and characteristics; Journal of Advanced Research, 24 (2), 91-98 doi.org/10.1016/j.jare.2020.03.005

${ }^{14}$ Jallal, C. 'Quantifying the impact of covid-19 on tanker trades'; Riviera, 2020; Adele, B. 'The Impact of covid19 on global shipping: Part 1, system shock'; Ship Technology; 2020 
thereby leading to an exorbitant price for the use of tankers while crude oil sellers are willing to pay for anyone to carry the crude oil in their respective tankers ${ }^{15}$.

Notably, oil tankers are employed in a normal setting for the purpose of transporting oil from an oil producing territory to where the end-user territory is located, especially in a case where there is no available pipeline for oil transportation. As of 2019 prior to the inception of covid-19, over 2 billion tons of crude oil and over 1 billion tons of petroleum products were transported across seas and oceans into specific countries by oil tankers. However, the state of the story changes with the occurrence of covid-19 which drastically reduced the oil demands across the globe and inadvertently affected the transportation of oil by oil tankers. It is because oil transportations via tankers declined exceedingly that led to a situation where oil tankers became a means of oil storage than main purpose of oil transportation. Thus, whereas the demand for tankers was high; the purpose for such surge in demand was unrelated to transportation as sellers and dealers of crude oil were only interested in getting a getting an oil tanker which can be utilised in the storage of oil and not necessarily for transportation ${ }^{16}$.

By the end of the second quarter of 2020, uncertainty have rocked the providers for bulk carrier vessels and the freight rates; this is owe to the significant impacts of the pandemic on the macroeconomic sectors which are drivers of supply and demand in the economy. Covid-19 led to a rancour amongst the international organizations responsible in the management of oil market. The supply and price pact brought into place by the apex oil market regulator (Organization of Petroleum Exporting Countries - OPEC) so as to maintain stability in the market, collapsed. The collapsed in the supply and price pacts amongst the exporting countries led to an unhealthy rivalry as countries fight over market shares ${ }^{17}$.

\section{Conclusion}

It is observed that an overview of the bulk carrier shipping appears obscure and depend extremely on the tints of lockdowns and inter-boundaries travel restrictions. According to BP. Accounts, demand for oil tanker transportation accounts for more than $50 \%$ of the global oil demand and with the rate of fall observed in oil prices, it is not expected that there will be a rebound to the rates at which the demands were at prior to covid-19 pandemic. Oil is at the bedrock of overall economic activities in the society, with the diminishing rate of oil

\footnotetext{
15 Takahiro, 'Why the tanker market was boosted by covid-19'; Mol-Services, 2020; Jallal, C. 'Quantifying the impact of covid-19 on tanker trades'; Riviera, 2020

${ }^{16}$ Jallal, C. 'Quantifying the impact of covid-19 on tanker trades'; Riviera, 2020

${ }^{17}$ IHS Markit, 'Spotlight on the impacts of covid-19 on the bulk carrier freight market'; Agricultural Business 
demand, which affects demand for oil tanker transportation; it follows that recovering the rate for freights to the pre-covid-19 level ${ }^{18}$.

While the longer-term impact of the COVID-19 outbreak is yet to be fully understood, all indicators are pointing to significant immediate challenges for the sector. These differ depending on the maritime transport segment (e.g. container, bulk, reefer, tanker) and whether the transport operation is domestic or international. They also vary by region, level of development, and the state of prior preparedness to shocks and disruptions. Countries with a high share of forward and backward global value chain participation are more vulnerable to supply chain disruptions ${ }^{19}$. Therefore, the study recommends that appropriate forecasting methods and proper liaison with global health will aid in averting or ameliorating the risks and negative impacts brought on shipping/oil tanker market by covid-19.

\section{Bibliography}

Adele, B. 'The Impact of covid-19 on global shipping: Part 1, system shock'; Ship Technology; 2020

Adnan, M. \& Siddiquea S.R; COVID-19 infection: Origin, transmission, and characteristics; Journal of Advanced Research, 24 (2), 91-98, (2020) doi.org/10.1016/i.jare.2020.03.005

BIMCO, 'Coronavirus is disrupting the supply of ships as well as demand'; 2020; Available on

https://www.bimco.org/news/market_analysis/2020/20200403_coronavirus_is_disrup ting the supply_of_ships_as_well_as_demand

British Ports Association, UK Ports: Coronavirus Economic Recovery Plan 2020 and Beyond. London; 2020

Coutroubis, A. D. Menelaou, A. A. and Adami, E. 'Impact of coronavirus disease (covid-19) on seafarers' life and well-being', International Journal of TROPICAL DISEASE \& Health 41(21): 16-27, 2020;

Dzau, V, Fuster, V, \& Frazer, J., Investing in global health for our future. N Engl J Med Overseas Ed; 377:1292-6. (2017); doi:10.1056/NEJMsr1707974

IHS Markit, 'Spotlight on the impacts of covid-19 on the bulk carrier freight market'; Agricultural Business Research and Analysis, 2020.

Jallal, C. 'Quantifying the impact of covid-19 on tanker trades'; Riviera, 2020

Philip, D. and Simon, H. Covid-19 container shipping market and operational issues update. Drewry Special Webinar. 14 May, 2020

\footnotetext{
${ }^{18}$ Adele, B. 'The Impact of covid-19 on global shipping: Part 1, system shock'; Ship Technology; 2020

${ }^{19}$ United Nations Conference on Trade and Development, 'COVID-19 and maritime transport: Impact and responses'; UNCTAD, 2020.
} 
Takahiro, 'Why the tanker market was boosted by covid-19'; Mol-Services, 2020; Jallal, C. 'Quantifying the impact of covid-19 on tanker trades'; Riviera, 2020

United Nations Conference on Trade and Development, 'COVID-19 and maritime transport: Impact and responses'; UNCTAD, 2020.

Vessels Value, 'Coronavirus causes China crude tanker demand to plummet', 2020; Available on https://www.oilandgasmiddleeast.com/products-services/36282coronavirus-causes-china-crude-tanker-demand-to-plummet-vesselsvalue

World Health Organization, Laboratory testing for coronavirus disease 2019 (COVID-19) in suspected human cases: interim guidance, (2020) 